\title{
Journal of Earth Energy Engineering
}

\author{
Publisher: Universitas Islam Riau (UIR) Press
}

\section{Completion Design for The Development of a Multi-Layer and Multi Fluid Reservoir Systemin Offshore Well AA-01, North-West Java}

Wijoyo Niti Daton ${ }^{1 *}$, Vincent Chandra ${ }^{1}$, Steven Chandra ${ }^{1}$

${ }_{1}^{1}$ Department of Petroleum Engineering, Institut Teknologi Bandung, Jl. Ganesha No. 10, Kec. Coblong, Bandung, West Java, Indonesia - 40132

*Corresponding Author: wndaton@gmail.com

\begin{tabular}{l}
\hline \hline Article History: \\
\hline Received: March 25, 2021 \\
Receive in Revised Form: May 29, 2021 \\
Accepted: June 8, 2021
\end{tabular}

Keywords:

Completion, multi-layer, multi-fluid, hydrocarbon, production.

\begin{abstract}
Completion systems are important components of hydrocarbon field development. As the link between the reservoir and surface facilities, completions need to be designed to maximize hydrocarbon recovery and withstand consistently changing conditions for years, within the safety requirements. However, designing completion for a well comprising a multi-layer and multi-fluid reservoir is quite challenging. The completion design must use the right materials and be able to safely produce single, as well as commingle products, and add any artificial lifts, depending on the method with the most optimum value. This paper, therefore, discusses the model development of completion design for an offshore well AA-01, one of the offshore wells with multi-layer and multi-fluid reservoir systems in Indonesia. Well AA-01 penetrates two productive layers, the upper layer AA-U1, and the lower layer AA-L2. The upper layer is a gas reservoir with initial gas in place of 1440 MMSCF, while the lower layer is an oil reservoir with initial oil in place of 6.1 MMSTB. In addition, the model design used available field data, for instance, PVT and DST, from well X. The base well completion was also used to model the completion design in software. Meanwhile, commercial software was utilized to estimate the well hydrocarbon recovery. Subsequently, several designs were tested, and the design with maximum production as well as hydrocarbon recovery was selected. The completion design selected comprises $95 / 8$ inch 47 ppf L-80 production casing, as well as $75 / 8$ inch 29.7 ppf L-80 liner, and produced commingle with oil and gas recovery of about $50.16 \%$ and $92.3 \%$, respectively, in 5 years production.
\end{abstract}

\section{INTRODUCTION}

Well development is a challenging task laden with high risks. Once a well has been drilled, the well must then be designated a producer, an injector, or be plugged and abandoned. Subsequently, completion works are carried out in cases where the well development is decided to be continued. Completions transform a drilled well into a producer or an injector. Currently, there are various types of well completion models, each with respective applicable conditions and limitations. However, only the most suitable well completion model is selected and developed to fully utilize the reservoir's potential. With the continuous developments in technology, completions have evolved to incorporate downhole sensors, leading to the creation of intelligent or smart wells. These sensors are able to measure rate, pressure, and gas-to-oil ratio, and are, therefore, useful for attaining optimum production. Certain wells have production flowing from multiple reservoir levels and types of fluid phase. These wells require more complex completions to ensure production.

A vast amount of technical information on multiphase flow in pipes is available in the literature (J.P. Brill \& Arirachakaran, 1992; James P Brill, 1987; Petalas \& Aziz, 2000). However, many of these sources are related to other industries. Multi-fluid flow in the petroleum industry has many distinct features creating complications unique to this industry. Furthermore, multi-fluid or multiphase flow is possible throughout the entire production system involved in conveying fluids from oil and gas reservoirs to processing facilities at the surface. The production system in this context includes the reservoir, the well completion, tubulars 
connecting the reservoir to the surface, as well as all surface facilities on land, seabed, or offshore platform, and any pipelines carrying the fluid produced to other processing facilities.

This paper, therefore, discusses the model development of completion design using commercial software. The model used data from an offshore well in Indonesia with a multi-layer and multi-fluid reservoir system. Furthermore, the reservoir in question comprises two layers with different types of fluid and characteristics. The upper layer is a gas reservoir, while the lower counterpart is an oil reservoir. Field data obtained from the well, including PVT, DST, and base model well completion, are used to develop the optimum completion design. The PVT data, for instance, pressure, temperature, gas to oil ratio, and saturation, are used to define the reservoir's characterization and are integrated with the base completions to estimate the well productivity index (PI) as well as the inflow performance relationship (IPR). Meanwhile, the DST data are used to determine the constructed IPR's validity. Subsequently, the base model is integrated into the software to predict the production. This is followed by combining several producing methods (single or commingle), casing sensitivities, and tubing sizes, are used to achieve the most optimum hydrocarbon recovery from the prediction results. Ultimately, the method with the best result is selected as the well completion design.

\section{Basic Theory}

\section{Completion System}

In addition to being a link between the reservoir and the surface facility, completion is applied as a combination of reservoir geology, reservoir engineering, and petroleum production engineering. The reservoir geology and reservoir engineering involve lithology, and the reservoir characteristics as well as flow characteristics, and these are theoretically, the basis for determining the completion design. Meanwhile, production engineering involves designating the well for production or injection and determining the production method, whether single separate zone production, commingle production, or added artificial lift (Bonapace \& Perazzo, 2016; Rytlewski, 2008).

\section{Casing and Tubing}

In well drilling, besides fulfilling the geologist's objectives of the well, there is a need to determine the well size and configuration, to maintain the wellbore stability and the well productivity. Figure 1 shows the most common casing size and hole size configurations, while Figure 2 shows the common conventional well configuration. Casing and tubing are essential in well completion. Wells drilled for oil and gas production or injection must be cased with materials of sufficient strength and functionality. A casing is series of steel pipes joined to create a continuous hollow tube running into a drilled well, to stabilize the wellbore. Furthermore, there are five types of casing, and these are conductor, surface, intermediate, production, and liner casings. Meanwhile, tubing is a smaller or slimmer casing used to transport fluids produced to the surface or transport injected fluid to formation. The tubing selection, design, and installation are critical to ensure efficient fluid flow and permit artificial lift installation.

Most countries follow the American Petroleum Institute (API) standards for casing and tubing design. Both designs must meet strict requirements for compression, tension, collapse, and burst resistance, and have the capacity to withstand hydraulic fracturing pressure, production pressures, as well as corrosive conditions. The API SPEC 5CT are the standards for casing and tubing design (Figure 1).

\section{Inflow Performance Relationship (IPR)}

Inflow Performance Relationship is defined as the relationship between flow rate and flowing bottom hole pressure. An IPR curve provides information including the well and reservoir deliverability and is combined with tubing relationship performance, to obtain optimum well performance.

- Oil well deliverability: An oil well's performance is estimated by the productivity index. Muskat (1941) proposed the constant productivity index concept is only appropriate for single-phase flow conditions oil wells with pressure above the reservoir bubble point pressure. The straight-line productivity index curve between flow rate and pressure does not apply to multiphase flow. Numerous empirical formulas have been proposed to predict oil well performance under twophase flow conditions. However, Vogel (1968) is the most popular and commonly used formula. The formula was the first to present an easy method for predicting oil well performance. This empirical inflow performance relationship (IPR) is based on computer simulation. The curve is generated using Vogel's equation for reservoir pressure below the bubble point pressure (Equation 1) and at bubble point pressure (Equation 2), as shown below. 


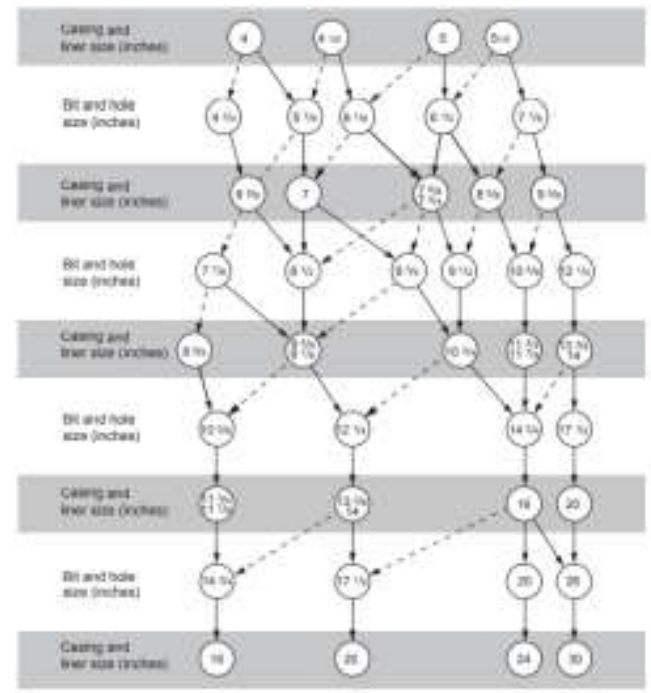

Figure 1. Casing String Size (Heriot Watt, 2005)

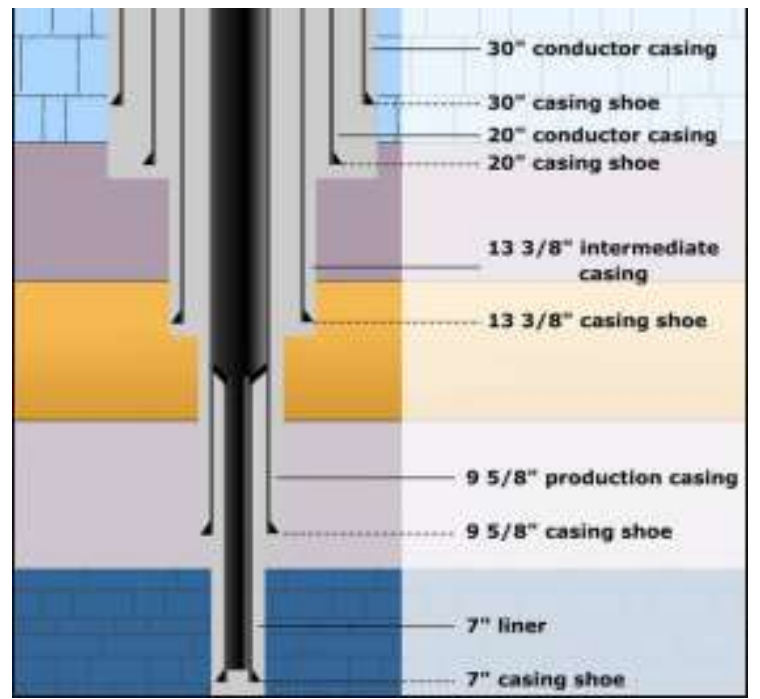

Figure 2. Conventional Well Configuration (drillingcourse.com, 2015)

$$
\begin{aligned}
\frac{q o}{q o, \max } & =1-0.2\left(\frac{P w f}{\bar{P} r}\right)-0.8\left(\frac{P w f}{\bar{P} r}\right)^{2} \\
\frac{q o}{q o, \max } & =1.8\left(\frac{P r}{P b}-\frac{P w f}{P b}\right)
\end{aligned}
$$

Another empirical formula used is the isochronal test proposed by fetkovich in 1973 . The deliverability equation is based on the empirical gas-well deliverability equation proposed by Rawlins \& Schellhardt (1935), as shown below.

$$
\begin{aligned}
& q o=C\left(\bar{P} r^{2}-P w f^{2}\right)^{n} \\
& \frac{q o}{q o, \max }=\left[1-\left(\frac{P w f}{\bar{P} r}\right)^{2}\right]^{2}
\end{aligned}
$$

Where, $\mathrm{C}$ represents the flow coefficient and $\mathrm{n}$ denotes the deliverability exponent, the inverse slope of the log-log plot of pressure-squared difference against flow rate. $\mathrm{C}$ and $\mathrm{n}$ are used to obtain the multiple rates. 
Table 1. PI SPEC 5CT - Specification for Casing and Tubing (drillingformulas.com)

\begin{tabular}{|c|c|c|c|c|c|c|c|c|}
\hline \multirow[t]{2}{*}{ No } & \multirow[t]{2}{*}{ O.D. (inch) } & \multirow{2}{*}{$\begin{array}{c}\text { Nominal } \\
\text { Weight } \\
\text { T \& c lbs/ft }\end{array}$} & \multirow[t]{2}{*}{ Grade } & \multirow{2}{*}{$\begin{array}{l}\text { Collapse } \\
\text { Pressure } \\
\text { (psi) }\end{array}$} & \multicolumn{4}{|c|}{$\begin{array}{l}\text { Internal yield Pressure } \\
\text { Minimum yield (psi) }\end{array}$} \\
\hline & & & & & PE & STC & LTC & BTC \\
\hline 1 & 7 & 38 & $\begin{array}{c}\text { HCN- } \\
80\end{array}$ & 12700 & 10800 & & 9240 & 8460 \\
\hline 2 & 7 & 38 & $\begin{array}{l}\mathrm{C}-90 \\
\mathrm{H} 2 \mathrm{~S}-\end{array}$ & 12820 & 12150 & & 10390 & 9520 \\
\hline 3 & 7 & 38 & 90 & 12820 & 12150 & & 10390 & 9520 \\
\hline 4 & 7 & 38 & S-95 & 13440 & 12830 & & 10970 & 10050 \\
\hline 5 & 7 & 38 & $\begin{array}{l}\text { T-95 } \\
\text { H2S- }\end{array}$ & 13440 & 12830 & & 10970 & 10050 \\
\hline 6 & 7 & 38 & 95 & & 12830 & & 10970 & 10050 \\
\hline 7 & 7 & 38 & C-95 & 13440 & 12830 & & 10970 & 10050 \\
\hline 8 & 7 & 38 & $\begin{array}{l}\mathrm{P}-110 \\
\mathrm{Q}-\end{array}$ & 15140 & 14850 & & 12700 & 11640 \\
\hline 9 & 7 & 38 & $\begin{array}{l}125 \\
\text { LS- }\end{array}$ & 16750 & 16880 & & 14430 & 13220 \\
\hline 10 & 7 & 38 & $\begin{array}{l}140 \\
\text { V- }\end{array}$ & 18280 & 18900 & & 16170 & 14810 \\
\hline 11 & 7 & 38 & 150 & 19240 & 20250 & & 17320 & 15870 \\
\hline 12 & 7 & 41 & $\begin{array}{l}\text { C-90 } \\
\text { H2S- }\end{array}$ & 13900 & 13280 & & 10390 & 9520 \\
\hline 13 & 7 & 41 & 90 & 13900 & 13280 & & 10390 & 9520 \\
\hline 14 & 7 & 41 & $\begin{array}{l}\text { T-95 } \\
\text { H2S- }\end{array}$ & 14670 & 14010 & & 10970 & 10050 \\
\hline 15 & 7 & 41 & 95 & 14670 & 14010 & & 10970 & 10050 \\
\hline 16 & 7 & 41 & $\begin{array}{l}\mathrm{P}-110 \\
\mathrm{Q}-\end{array}$ & 16990 & 16230 & & 12700 & 11640 \\
\hline 17 & 7 & 41 & $\begin{array}{l}125 \\
V-\end{array}$ & 19300 & 18440 & & 14430 & 13220 \\
\hline 18 & 7 & 41 & 150 & 22820 & 22130 & & 17320 & 15870 \\
\hline 19 & 7 & 42.7 & C-90 & 14640 & 14060 & & & \\
\hline 20 & 7 & 42.7 & T-95 & 15450 & 14840 & & & \\
\hline 21 & 7 & 46.4 & C-90 & 15930 & 15460 & & & \\
\hline 22 & 7 & 46.4 & T-95 & 16820 & 16320 & & & \\
\hline 23 & 7 & 50.1 & C-90 & 17220 & 16880 & & & \\
\hline 24 & 7 & 50.1 & T-95 & 18810 & 17810 & & & \\
\hline 25 & 7 & 53.6 & C-90 & 18460 & 18270 & & & \\
\hline 26 & 7 & 53.6 & T-95 & 19480 & 19290 & & & \\
\hline 27 & 7 & 57.1 & C-90 & 19690 & 19690 & & & \\
\hline 28 & 7 & 57.1 & T-95 & 20780 & 20780 & & & \\
\hline 29 & $75 / 8$ & 24 & $\mathrm{H}-40$ & 2030 & 2750 & 2750 & & \\
\hline 30 & $75 / 8$ & 26.4 & J-55 & 2890 & 4140 & 4140 & 4140 & 4140 \\
\hline 31 & $75 / 8$ & 26.4 & K-55 & 2890 & 4140 & 4140 & 4140 & 4140 \\
\hline 32 & $75 / 8$ & 26.4 & LS-65 & 3100 & 4890 & 4890 & 4890 & 4890 \\
\hline 33 & $76 / 8$ & 26.4 & $\begin{array}{l}\text { L-80 } \\
\text { HCL- }\end{array}$ & 3400 & 6020 & & 6020 & 6020 \\
\hline 34 & $75 / 8$ & 26.4 & 80 & 4850 & 6020 & & 6020 & 6020 \\
\hline 35 & $75 / 8$ & 26.4 & $\mathrm{~N}-80$ & 3400 & 6020 & & 6020 & 6020 \\
\hline
\end{tabular}




\begin{tabular}{|c|c|c|c|c|c|c|c|c|c|c|}
\hline 36 & & $75 / 8$ & & 26.4 & $\begin{array}{l}\text { C-90 } \\
\text { H2S- }\end{array}$ & 3610 & 6780 & & 6780 & 6780 \\
\hline 37 & & $75 / 8$ & & 26.4 & 90 & 4850 & 6780 & & 6780 & 6780 \\
\hline 38 & & $75 / 8$ & & 26.4 & S-95 & 4850 & 7150 & & 7150 & 7150 \\
\hline 39 & & $75 / 8$ & & 26.4 & $\begin{array}{l}\text { T-95 } \\
\text { H2S- }\end{array}$ & 3710 & 7150 & & 7150 & 7050 \\
\hline 40 & & $75 / 8$ & & 26.4 & 95 & 4850 & 7150 & & 7150 & 7050 \\
\hline \multirow[t]{2}{*}{ No } & \multicolumn{3}{|c|}{$\begin{array}{l}\text { Joint Strenght } \\
1000 \mathrm{lbs}\end{array}$} & $\begin{array}{l}\text { Body Yield } \\
1000 \mathrm{lbs}\end{array}$ & $\begin{array}{l}\text { Wall } \\
\text { (inch) }\end{array}$ & I.D. (inch) & $\begin{array}{c}\text { Drift } \\
\text { Diameter } \\
\text { (inch) }\end{array}$ & $\begin{array}{l}\text { Displacement } \\
\text { (bbl/ft) }\end{array}$ & & $\begin{array}{r}\text { Capacity } \\
\text { (bbl/ft) }\end{array}$ \\
\hline & STC & LTC & BTC & & & & & & & \\
\hline 1 & & 831 & 876 & 877 & 0.54 & 5.92 & 5.795 & 0.01356 & & 0.03405 \\
\hline 2 & & 883 & 876 & 986 & 0.54 & 5.92 & 5.795 & 0.01356 & & 0.03405 \\
\hline 3 & & 883 & 876 & 986 & 0.54 & 5.92 & 5.795 & 0.01356 & & 0.03405 \\
\hline 4 & & 944 & 964 & 1041 & 0.54 & 5.92 & 5.795 & 0.01356 & & 0.03405 \\
\hline 5 & & 931 & 920 & 1041 & 0.54 & 5.92 & 5.795 & 0.01356 & & 0.03405 \\
\hline 6 & & 931 & 920 & 1041 & 0.54 & 5.92 & 5.795 & 0.01356 & & 0.03405 \\
\hline 7 & & 931 & 920 & 1041 & 0.54 & 5.92 & 5.795 & 0.01356 & & 0.03405 \\
\hline 8 & & 1067 & 1096 & 1205 & 0.54 & 5.92 & 5.795 & 0.01356 & & 0.03405 \\
\hline 9 & & 1207 & 1183 & 1370 & 0.54 & 5.92 & 5.795 & 0.01356 & & 0.03405 \\
\hline 10 & & 1341 & 1315 & 1534 & 0.54 & 5.92 & 5.795 & 0.01356 & & 0.03405 \\
\hline 11 & & 1430 & 1402 & 1644 & 0.54 & 5.92 & 5.795 & 0.01356 & & 0.03405 \\
\hline 12 & & 903 & 876 & 1069 & 0.59 & 5.82 & 5.695 & 0.01470 & & 0.03290 \\
\hline 13 & & 903 & 876 & 1069 & 0.59 & 5.82 & 5.695 & 0.01470 & & 0.03290 \\
\hline 14 & & 952 & 920 & 1129 & 0.59 & 5.82 & 5.695 & 0.01470 & & 0.03290 \\
\hline 15 & & 950 & 920 & 1129 & 0.59 & 5.82 & 5.695 & 0.01470 & & 0.03290 \\
\hline 16 & & 1111 & 1096 & 1307 & 0.59 & 5.82 & 5.695 & 0.01470 & & 0.03290 \\
\hline 17 & & 1244 & 1183 & 1485 & 0.59 & 5.82 & 5.695 & 0.01470 & & 0.03290 \\
\hline 18 & & 1488 & 1402 & 1782 & 0.59 & 5.82 & 5.695 & 0.01470 & & 0.03290 \\
\hline 19 & & & & 1127 & 0.625 & 5.75 & 5.625 & 0.01548 & & 0.03212 \\
\hline 20 & & & & 1189 & 0.625 & 5.75 & 5.625 & 0.01548 & & 0.03212 \\
\hline 21 & & & & 1226 & 0.687 & 5.626 & 5.5 & 0.01685 & & 0.03075 \\
\hline 22 & & & & 1294 & 0.687 & 5.626 & 5.5 & 0.01685 & & 0.03075 \\
\hline 23 & & & & 1325 & 0.75 & 5.5 & 5.375 & 0.01821 & & 0.02939 \\
\hline 24 & & & & 1399 & 0.75 & 5.5 & 5.375 & 0.01821 & & 0.02939 \\
\hline 25 & & & & 1421 & 0.812 & 5.376 & 5.251 & 0.01952 & & 0.02808 \\
\hline 26 & & & & 1500 & 0.812 & 5.376 & 5.251 & 0.01952 & & 0.02808 \\
\hline 27 & & & & 1515 & 0.875 & 5.25 & 5.125 & 0.02083 & & 0.02678 \\
\hline 28 & & & & 1600 & 0.875 & 5.25 & 5.125 & 0.02083 & & 0.02678 \\
\hline 29 & 212 & & & 276 & 0.3 & 7.025 & 6.9 & 0.00854 & & 0.04794 \\
\hline 30 & 315 & 346 & 483 & 414 & 0.328 & 6.969 & 6.844 & 0.00930 & & 0.04718 \\
\hline 31 & 342 & 377 & 581 & 414 & 0.328 & 6.969 & 6.844 & 0.00930 & & 0.04718 \\
\hline 32 & 368 & 403 & 554 & 489 & 0.328 & 6.969 & 6.844 & 0.00930 & & 0.04718 \\
\hline 33 & & 482 & 635 & 602 & 0.328 & 6.969 & 6.844 & 0.00930 & & 0.04718 \\
\hline 34 & & 533 & 691 & 602 & 0.328 & 6.969 & 6.844 & 0.00930 & & 0.04718 \\
\hline 35 & & 490 & 659 & 602 & 0.328 & 6.969 & 6.844 & 0.00930 & & 0.04718 \\
\hline 36 & & 532 & 681 & 677 & 0.328 & 6.969 & 6.844 & 0.00930 & & 0.04718 \\
\hline
\end{tabular}




\begin{tabular}{lllllllll}
37 & 553 & 691 & 677 & 0.328 & 6.969 & 6.844 & 0.00930 & 0.04718 \\
38 & 568 & 740 & 714 & 0.328 & 6.969 & 6.844 & 0.00930 & 0.04718 \\
39 & 560 & 716 & 714 & 0.328 & 6.969 & 6.844 & 0.00930 & 0.04718 \\
40 & 560 & 716 & 714 & 0.328 & 6.969 & 6.844 & 0.00930 & 0.04718 \\
\hline
\end{tabular}

- Gas well deliverability: Deliverability testing is performed to determine the productivity of a gas well. Gas well deliverability tests are used to predict the flow rate of a gas well during reservoir depletion. An empirical relationship was proposed by Rawlins \& Schellhardt (1935) and is frequently used today. The empirical backpressure method of testing gas wells is based on the analysis of results obtained from testing over 500 wells. The difference between the squares of the average reservoir pressure and flowing bottom hole pressures were plotted against the flow rates on logarithmic coordinates to obtain a straight-line graph. This led Rawlins \& Schellhardt (1935) to propose the backpressure equation (Equations 3 and 4).

\section{Nodal Analysis}

In the production system, reservoir performance and piping system performance are inseparable and interdependent. Fluid transported from the reservoir to the surface through the tubular or flowline requires pressure difference to move. The amount of fluid transported into a well from the reservoir relies more on the pressure drop in the piping system, and the piping system's pressure depends on the amount of fluid flowing through it. Therefore, the entire production system must be analyzed as a unit. Nodal analysis is a tool used to attain optimum well design in terms of perforations, tubing size, and underbalance design. This analysis is applied in both oil and gas wells, as well as many other well systems, and is able to simulate impacts in the variations of tubing size, choke size, surface pressure, and inflow on the well's performance. The nodal analysis aims to combine the various components of the production system for an individual well, to estimate production rates and optimize the production system's components (Awal \& Heinze, 2009).

\section{METHODOLOGY}

Figure 3 shows the methodology or workflow of this project.

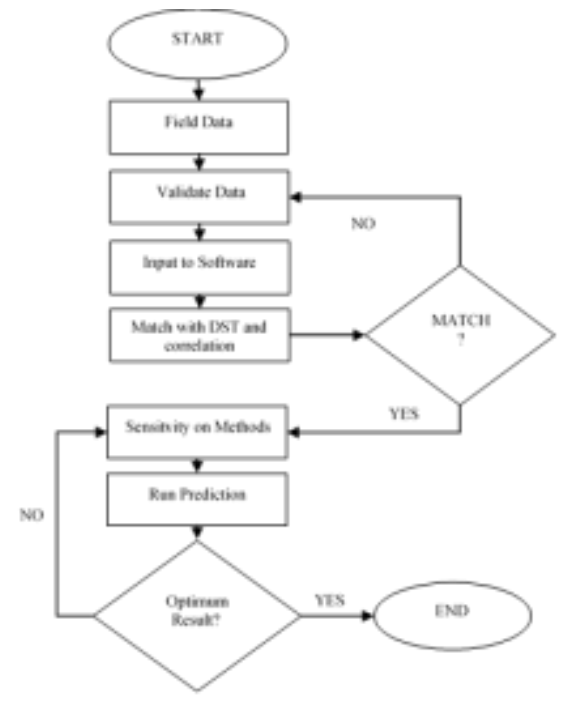

Figure 3. Workflow Chart

\section{Data Validation}

Analysis of a multi-layer and multi-fluid reservoir well is quite difficult and tricky, due to well complexity. In some cases, the fluid remains in the wellbore before well testing, leading to data inaccuracy for instance, in the fluid rate, flowing wellhead pressure, or gas-to-oil ratio. In this project, the field data was validated by inputting it into the first commercial software. This was carried out to ensure the field data represents the actual reservoir. In the software, the input data is then validated using various available correlations. The software is used to validate several data, from the reservoir data to well completion. 
After testing all the correlations, the data is corrected in cases where the data did not match the actual well data obtained DST. From the field data, invalid data was discovered on DST for the oil reservoir. Based on Figure 4, the gas-oil ratio (GOR) is a bit off. Subsequently, the data were corrected using simple linear regression and the corrected result was obtained (Figure 5). The GOR required correction because the incorrect data affected the calculation of flowing bottom-hole pressure (Pwf), and consequently, the IPR calculation. In this study, the Pwf calculation was based on Cullender \& Smith (1956) method for the gas reservoir, as well as the Poettman \& Carpenter (1952) method for the oil reservoir. Data validation was necessary to ensure the data obtained are the exact data produced from the actual reservoir to the well, thus, minimalizing error in advanced simulation. The project then proceeded after data validation had been performed.

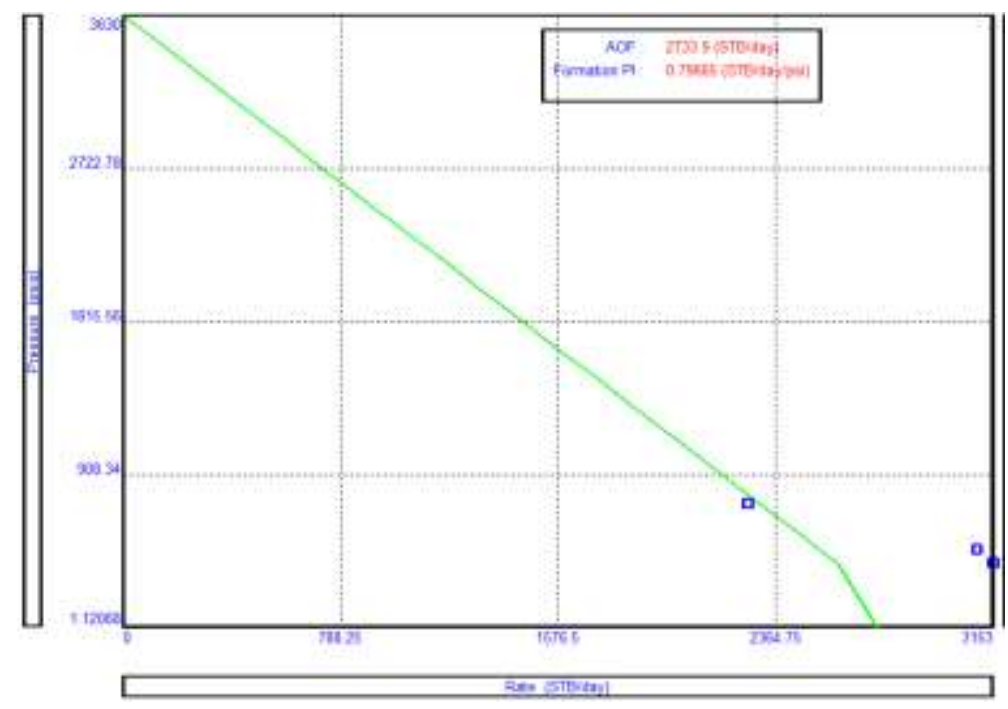

Figure 4. Vogel IPR before data validation

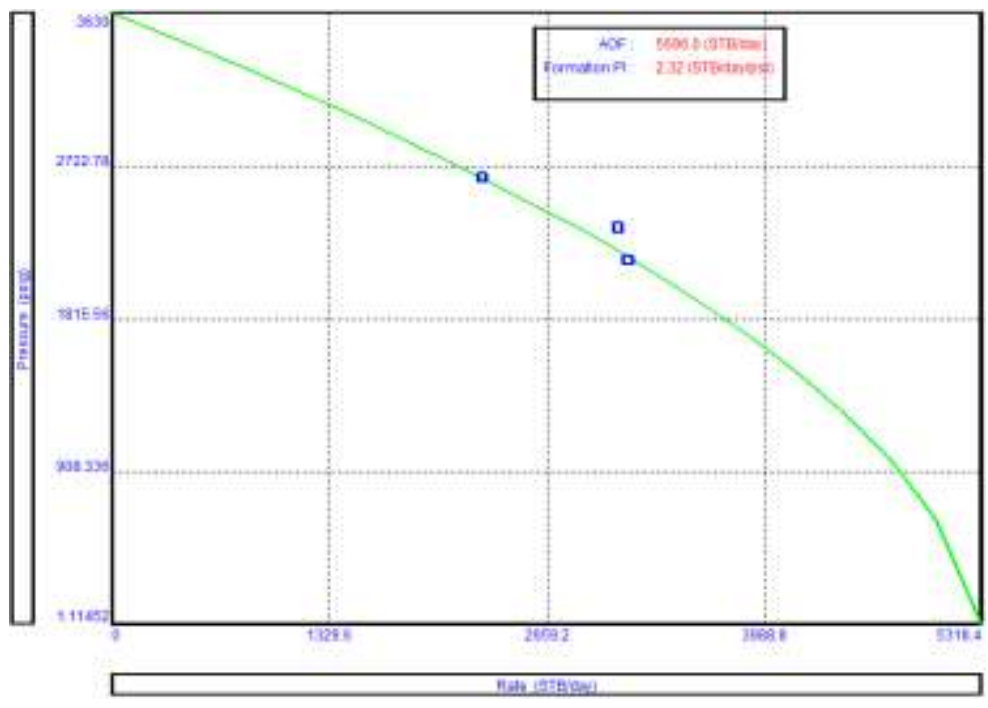

Figure 5. Vogel IPR after data validation

\section{Production Data Matching}

After all the data were validated, the model was matched with the available correlations for constructing the IPR curve, based on the data availability and reservoir characterization. The IPR for the oil reservoir with the best match correlation was found to be the Vogel method (Figure 5), while the gas reservoir counterpart was the multi-rate $\mathrm{C}$ and $\mathrm{n}$ method (Figure 6).

Subsequently, the vertical lift performance relationship (VLP) or tubing performance relationship (TPR) was determined. The field data, including the measured depth, true vertical depth, well schematic, as well as casing and tubing sizes, were inputted into the first software, to determine the VLP. Based on the correlation sensitivity and the VLP results, the best match for the gas reservoir was found to be Beggs and 
Brill (Figure 7), while the oil reservoir counterpart was found to be Petroleum Expert (Figure 8) for oil reservoir. Figures 9 and 10 show the VLP/IPR curve constructed using the selected correlations.

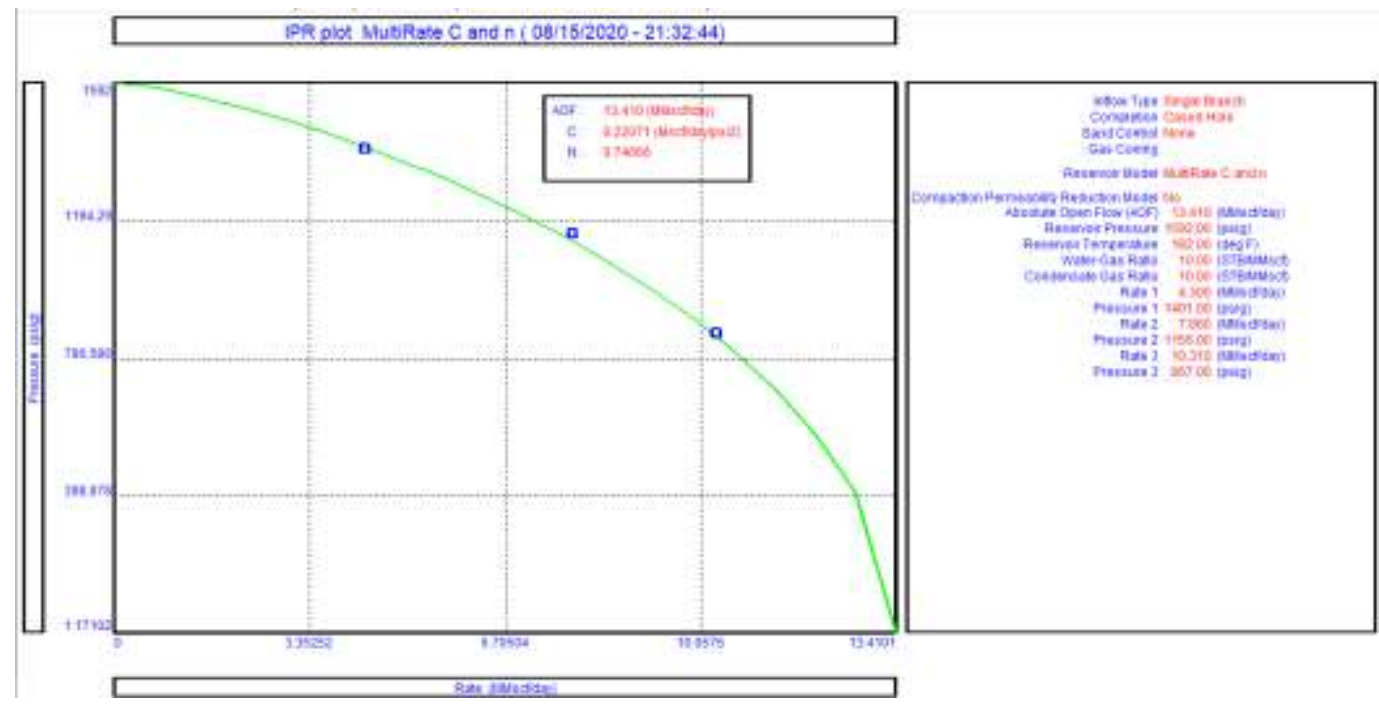

Figure 6. IPR model for Gas Zone in well X-1

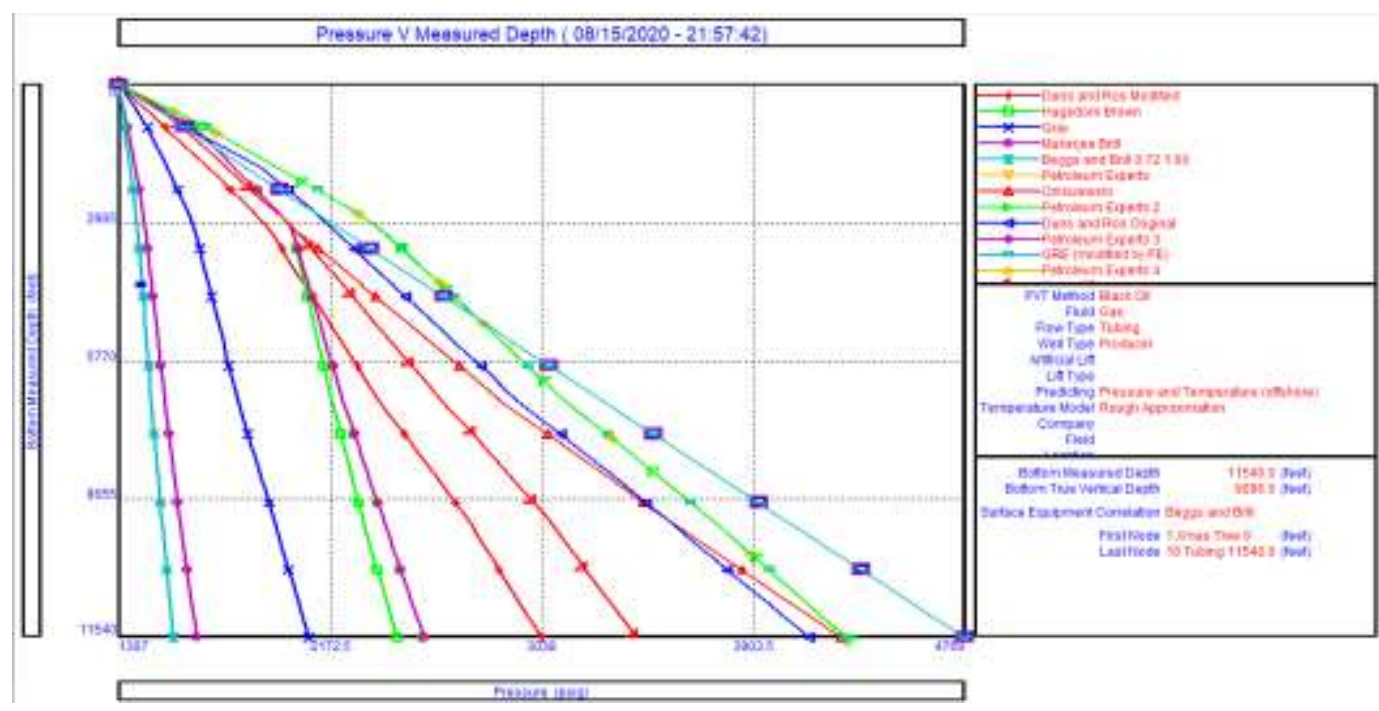

Figure 7. Tubing Performance Correlation Comparison for Gas Reservoir Zone

\section{Run Prediction}

The results from the first software were integrated into a second commercial software, to carry out the production prediction. Figure 11 shows the model used to run the production prediction, for 5 years with time step per week. The sensitivity of the production method (Table 2), as well as the casing and tubing sizes (Table 3), were determined, based on the most common casing size and hole size configurations (Figure 1), as well as API SPEC 5CT. 


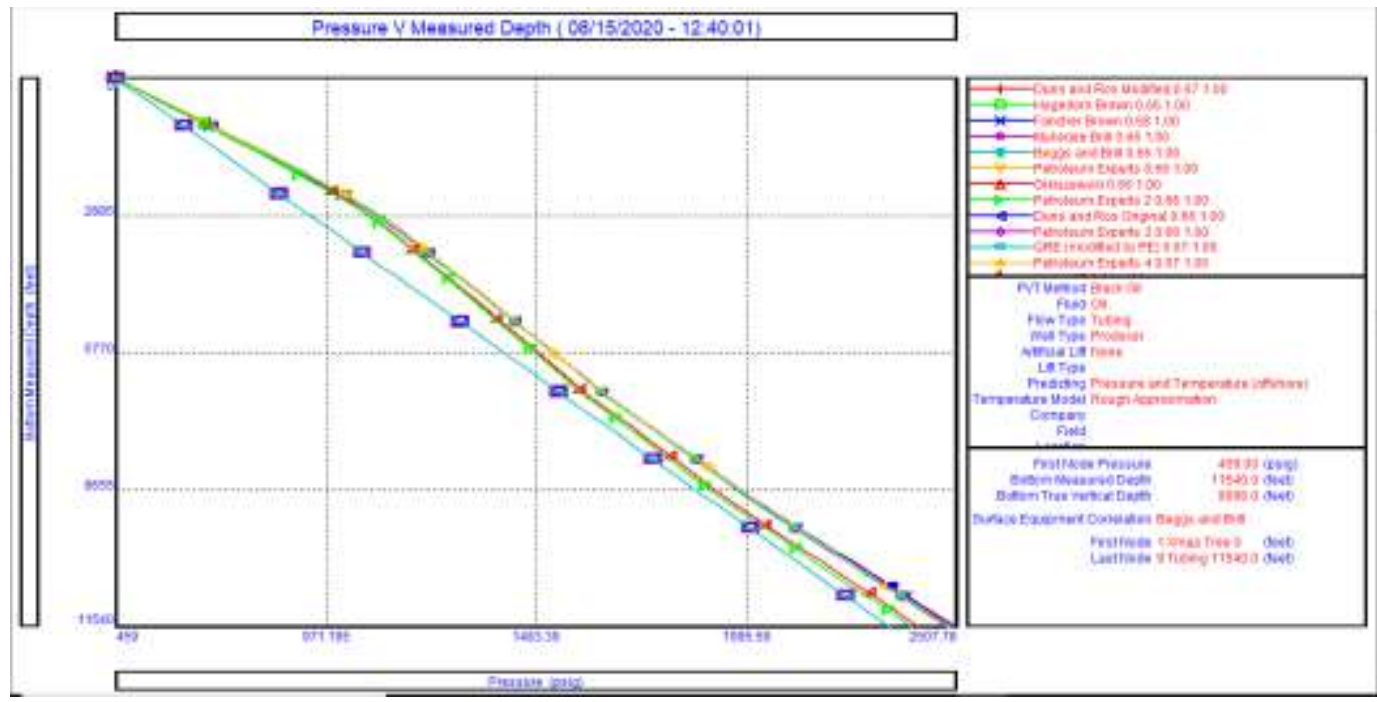

Figure 8. Tubing Performance Correlation Comparison for Oil Reservoir Zone

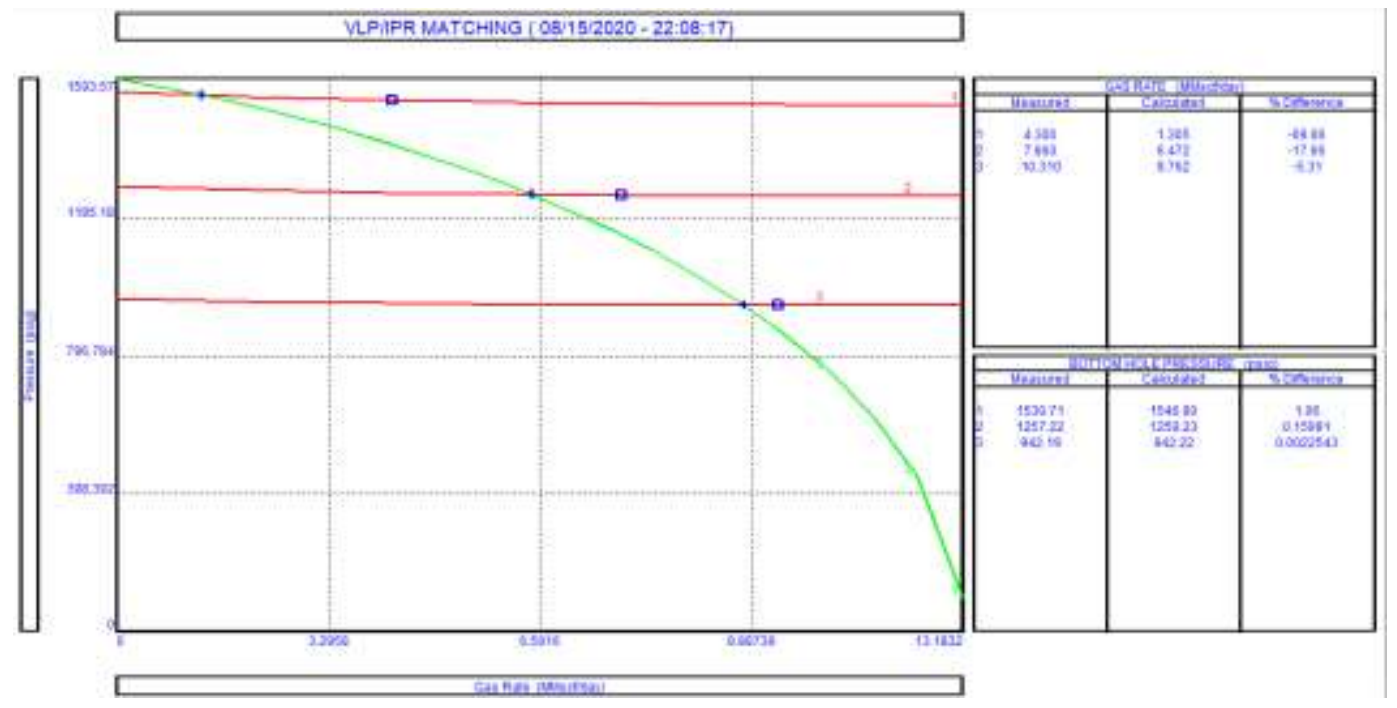

Figure 9. VLP/IPR plot using Beggs and Brill correlation

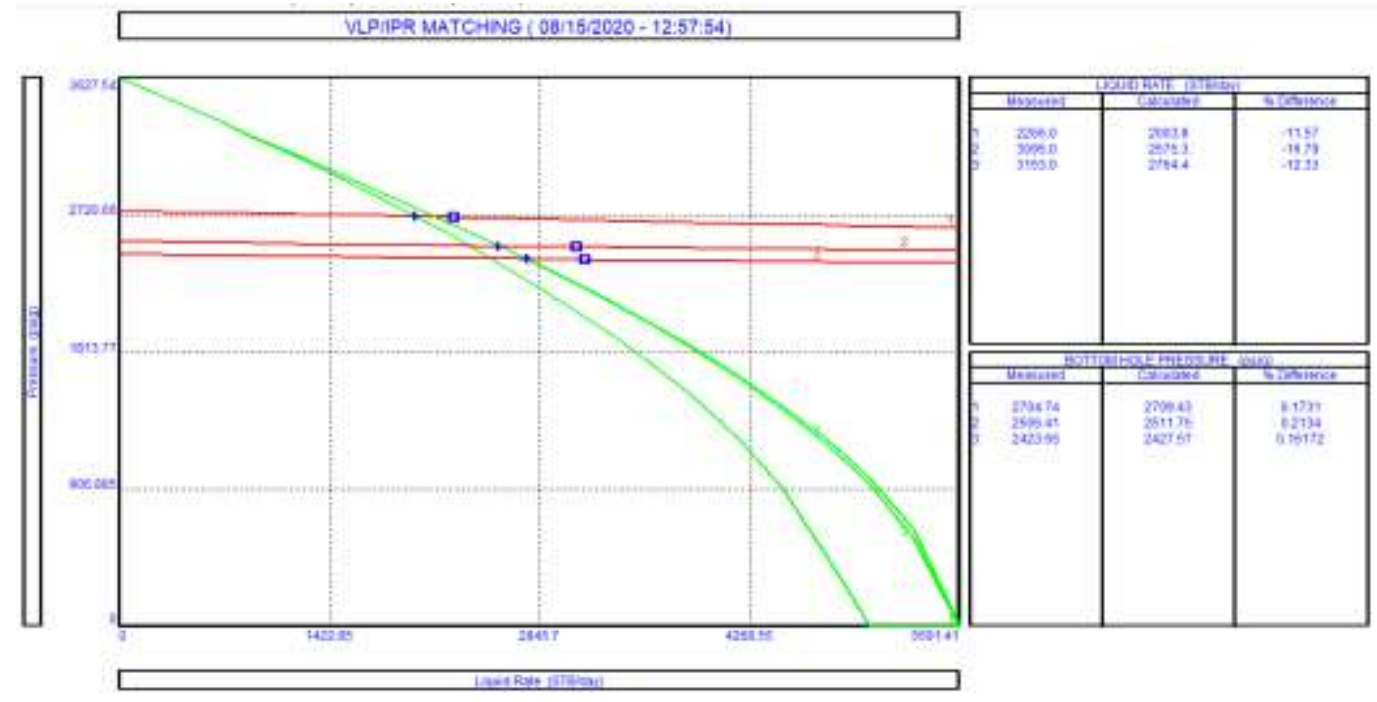

Figure 10. VLP/IPR plot using Petroleum Expert correlation 


\section{Case Study}

An offshore well in Indonesia was used as the case study in this project. The well is deviated and comprises two main layers with different types of fluid. The Upper layer AA-U1 is a gas reservoir, while the lower layer AA-L2 is an oil reservoir. Furthermore, the well is drilled to 9,096 ft TVD (11,540 ft MD), using a jack-up rig comprising a 30-inch conductor casing, 18 5/8 inch, 87 ppf, K-55 surface casing, 133/8 inch, 61 ppf, K-55 intermediate casing, 95/8 inch, 47 ppf, L-80 production casing, and a 7 inch, 26 ppf, L-80 liner (Figure 12). The assumptions used in this project are outlined below.

- The aquifer's boundary,

- Constants Bo, WC, CGR, WGR, and GOR, in prediction.

- No sand problems and water coning.

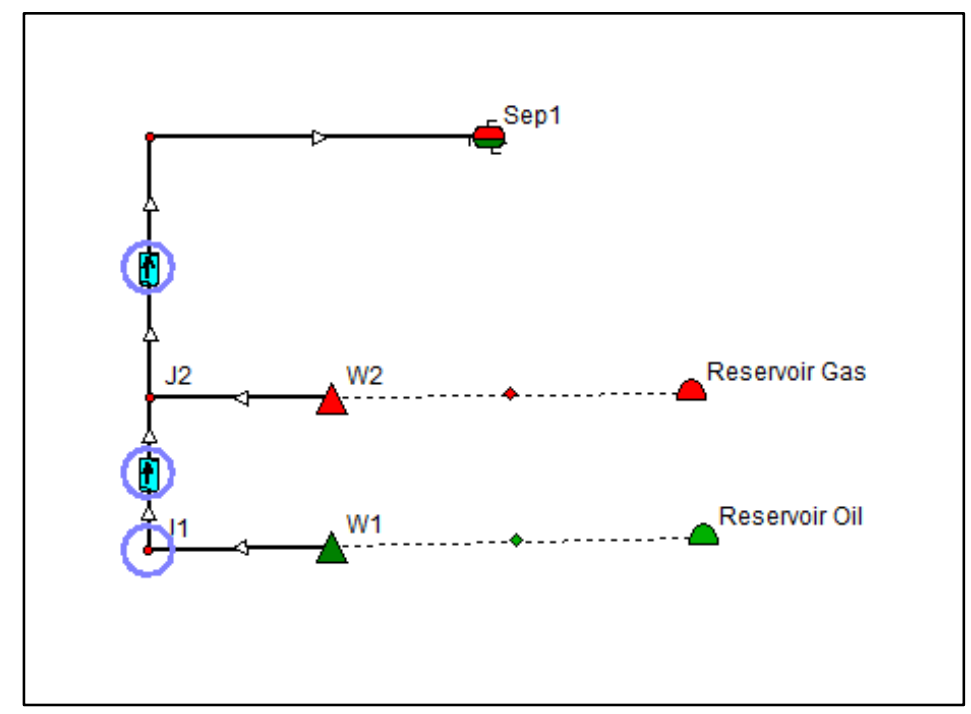

Figure 11. Well Design Model for Running Prediction

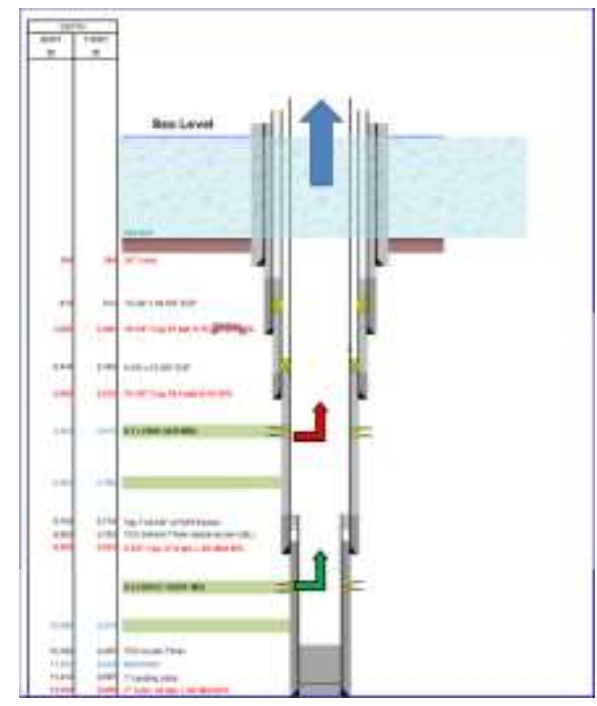

Figure 12. Existing Well X Completion 
Table 2. Production Method for Running Prediction

\begin{tabular}{cc}
\hline Production Method & Description \\
\hline Single & Gas Only \\
& Oil Only \\
Commingle & Gas and Oil \\
\hline
\end{tabular}

Table 3. Casing and Tubing Specification for Running Prediction

\begin{tabular}{cccc}
\hline $\begin{array}{c}\text { Production } \\
\text { Casing (inch) }\end{array}$ & $\begin{array}{c}\text { Tubing or Liner } \\
\text { (inch) }\end{array}$ & $\begin{array}{c}\text { Nominal Weight } \\
\text { (ppf) }\end{array}$ & $\begin{array}{c}\text { Collapse } \\
\text { Pressure (psi) }\end{array}$ \\
\hline & $65 / 8$ & 24 & 5760 \\
& & 28 & 8170 \\
& 7 & 23 & 3830 \\
& & 26 & 5410 \\
& $75 / 8$ & 29.7 & 4790 \\
& $73 / 4$ & 33.7 & 6560 \\
& & 46.1 & 11340 \\
\hline
\end{tabular}

\section{Upper Layer}

Layer AA-U1 is a gas reservoir with initial gas in place of 1440 MMSCF and a reservoir pressure of 1594 psia. The layer is produced at $4184^{\prime}-4215^{\prime}$ MD through the 95/8 inch production casing. Tables 4 and 5 show the reservoir's other properties and the DST data, respectively.

Table 4. Gas Fluid Properties

\begin{tabular}{ccc}
\hline Parameters & Unit & Value \\
\hline Condensate API Gravity & API & 55 \\
SG Gas & sp. Gravity & 0.688 \\
WGR & STB/MMSCF & 10 \\
CGR & STB/MMSCF & 10 \\
Temperature & $0 \mathrm{~F}$ & 182 \\
Initial Pressure & psi & 1594 \\
Porosity & fraction & 0.25 \\
S $_{\mathrm{wc}}$ & fraction & 0.35 \\
Water Compressibility & $1 / \mathrm{psi}$ & $3 \mathrm{E}-06$ \\
\hline
\end{tabular}

Table 5. Upper layer DST data

\begin{tabular}{cccccccc}
\hline DST & $\begin{array}{c}\text { Choke } \\
\text { Size }\end{array}$ & $\begin{array}{c}\text { Oil } \\
(\text { BOPD })\end{array}$ & $\begin{array}{c}\text { Gas } \\
(\text { MMSCFD })\end{array}$ & $\begin{array}{c}\text { Water } \\
(\text { BWPD })\end{array}$ & $\begin{array}{c}\text { FWHP } \\
(\mathrm{psi})\end{array}$ & $\begin{array}{c}\text { FWHT } \\
\left({ }^{\circ} \mathrm{F}\right)\end{array}$ & $\begin{array}{c}\text { Chloride } \\
(\mathrm{ppm})\end{array}$ \\
\hline AA- & $32 / 64$ & 1 & 4.30 & 1 & 1307 & 113 & 58000 \\
U1 & $48 / 64$ & 70 & 7.86 & 33 & 1081 & 128 & 44000 \\
& $64 / 64$ & 156 & 10.31 & 74 & 811 & 135 & 40000 \\
\hline
\end{tabular}




\section{Lower Layer}

Layer AA-L2 is an oil reservoir with initial oil in place of 6.1 MMSTB and a reservoir pressure of 3630 psia. The layer is produced at 10,655'-10,691' MD through the 7-inch liner. Tables 6 and 7 show the reservoir's other properties and the DST data, respectively.

Table 6. Oil Fluid Properties

\begin{tabular}{ccc}
\hline Parameter & Unit & Value \\
\hline Oil API Gravity & API & 29 \\
SG Gas & sp. Gravity & 1.18 \\
GOR & scf/STB & 537 \\
WCT & Persen & 10 \\
Temperature & $0 \mathrm{~F}$ & 283 \\
Initial Pressure & psi & 3630 \\
Porosity & fraction & 0.12 \\
Swc & fraction & 0.3 \\
Water Compressibility & $1 /$ psi & $3 \mathrm{E}-06$ \\
\hline
\end{tabular}

Table 7. Lower layer DST data

\begin{tabular}{ccccccc}
\hline DST & Choke Size & $\begin{array}{c}\text { Oil } \\
\text { (BOPD) }\end{array}$ & $\begin{array}{c}\text { Gas } \\
\text { (MMSCFD) }\end{array}$ & $\begin{array}{c}\text { Water } \\
\text { (BWPD) }\end{array}$ & $\begin{array}{c}\text { FWHP } \\
\text { (psi) }\end{array}$ & GOR \\
\hline \multirow{3}{*}{ AA-L2 } & $32 / 64$ & 2266 & 1.21 & 0 & 730 & 534 \\
& $48 / 64$ & 3095 & 1.67 & 0 & 459 & 539.9 \\
& $64 / 64$ & 3153 & 1.19 & 0 & 380 & 377.4 \\
\hline
\end{tabular}

\section{RESULT AND DISCUSSION}

In comparison with the existing well completion, the new model did not change excessively, but provided a slightly better hydrocarbon recovery, compared to the base model (Figure 13). The completion selected is the $95 \%$ inch 47 ppf L-80 production casing and 75/8 inch 29.7 ppf L-80 liner, with oil and gas recovery of $50.16 \%$ and $92.3 \%$, respectively. Meanwhile, the production method selected was commingled production, with some constraints for the upper layer. The upper layer reservoir was predicted to produce at full potential for only 2 years. The production casing was not changed because the layer is going to produce for 2 years, thus changing the casing is not economical. In addition, the tested liners were the $6 \% / 8$ inch, 7 -inch, $75 / 8$ inch, and $73 / 4$, with the specification based on the reservoir profile pressure, compared to the collapse pressure provided in API SPEC 5CT, and the selected liner was the 75/8 inch $29.7 \mathrm{ppf}$ L-80 liner.

The oil rate decreased from 2795.2 STB/day on the first day to $1594.6 \mathrm{STB} /$ day after 5 years prediction, while the gas rate decreases from $13.854 \mathrm{MMSCF} /$ day to $0.856 \mathrm{MMSCF} /$ day (Figure 14). The high decreasing rate occurred because the well was producing at full capacity. In addition, the reservoir is assumed to be volumetric, due to inadequate driving mechanism data. Also, the aquifer reservoir is another constrain on the production result.

This project method is recommendable and possibly reliable for model completions. However, this model development method requires improvement to be fully applicable, because numerous assumptions were used in this study. Furthermore, the software's inability to consider all applied limitations and constraints led to the use of a less efficient method, and consequently, the obstruction of results with more potential. This project did discover any problems, however, considering the flow type's dynamic characteristics, certain problems, including slug flow and cross-flow, are bound to occur as the reservoir becomes depleted. Therefore, to minimalize the problems in the future, dual string completion ought to be used. However, this model is more expensive, compared to this study's model. Also, artificial lifts ought to be added in the future, to improve hydrocarbon recovery. 


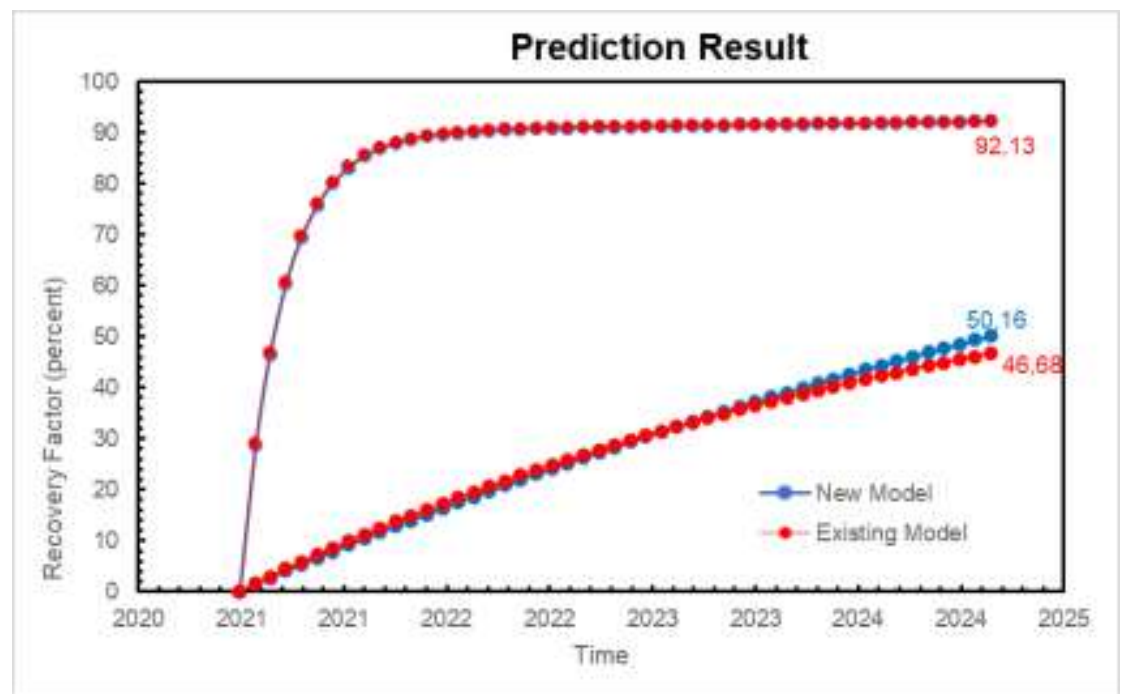

Figure 13. New model vs Existed model Recovery Factor Comparison

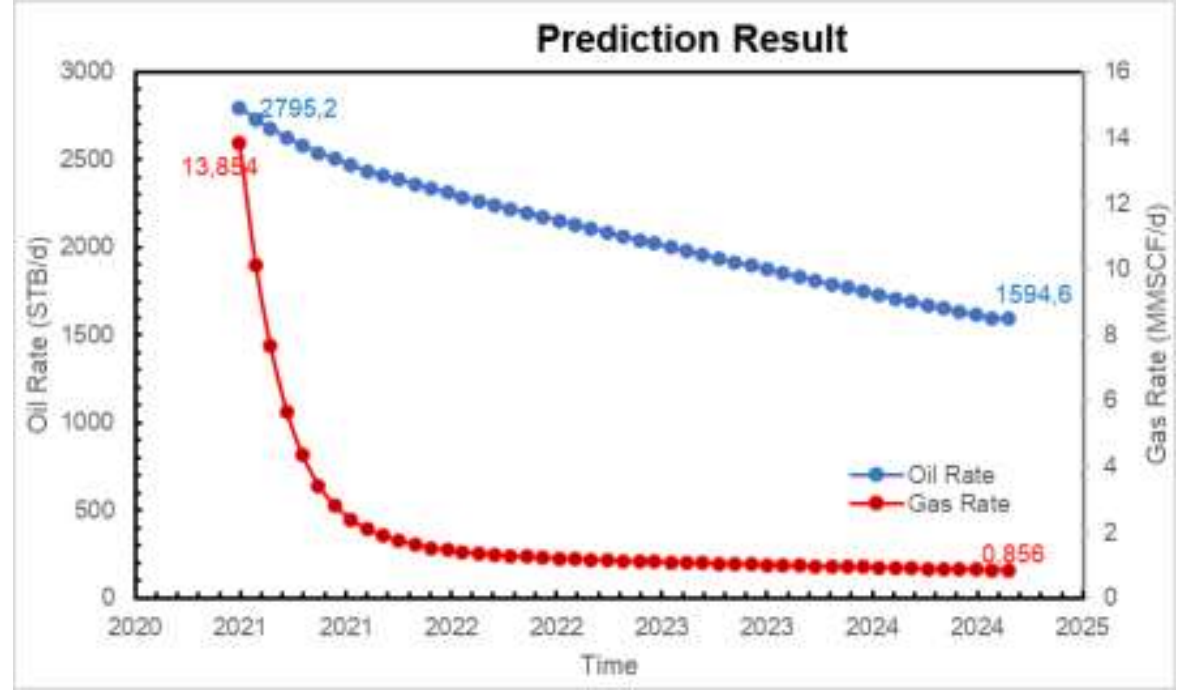

Figure 14. Oil and Gas Rate Comparison

\section{CONCLUSION}

The proposed design is completion with 95/8 inch $47 \mathrm{ppf}$ L-80 production casing, and 7\%/8 inch $29.7 \mathrm{ppf} \mathrm{L}-80$ liner. In addition, the existing well $\mathrm{X}$ completion produces good results, however, the new model's result is slightly better, due to the use of a bigger liner, with oil and gas recovery of $50.16 \%$ and $92.3 \%$, respectively. This is probably because a smaller size leads to a higher flow rate, but quickly reduces the reservoir pressure, in cases where the rate is not controlled properly.

\section{Nomenclature}

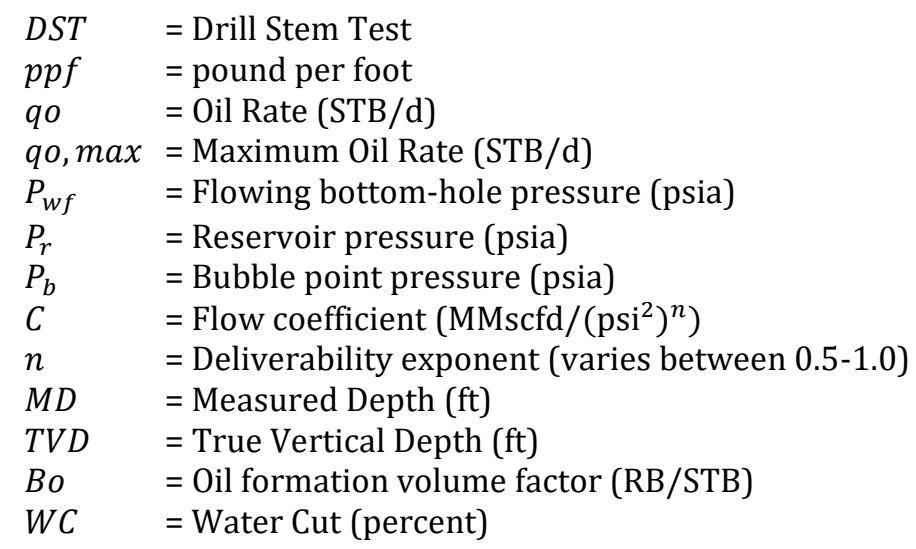


CGR = Condensate Gas Ratio (bbl/scf)

$W G R \quad=$ Water Gas Ratio (bbl/scf)

GOR = Gas Oil Ratio $(\mathrm{scf} / \mathrm{bbl})$

\section{REFERENCES}

Awal, M. R., \& Heinze, L. R. (2009). A New Nodal-Analysis Technique to Improves Well Completion and Economic Performance of a Matured Oil Field. The SPE Production and Operations Symposium, 556566. https://doi.org/10.2118/120632-MS

Bonapace, J. C., \& Perazzo, G. (2016, November 12). Vertical Well Completions in Multilayer Reservoirs: A Decade of Technologies Implemented in Argentina. The International Petroleum Technology Conference. https://doi.org/10.2523/IPTC-18629-MS

Brill, J.P., \& Arirachakaran, S. J. (1992). State of the Art in Multiphase Flow. Journal of Petroleum Technology, 44(05), 538-541. https://doi.org/10.2118/23835-PA

Brill, James P. (1987). Multiphase Flow in Wells. Journal of Petroleum Technology, 39(January), 15-21.

Cullender, M. H., \& Smith, R. V. (1956). Practical Solution of Gas-Flow Equations for Wells and Pipelines with Large Temperature Gradients. Transactions of the AIME, 207(01), 281-287. https://doi.org/10.2118/696-G

Evinger, H. H., \& Muskat, M. (1942). Calculation of Theoretical Productivity Factor. Transactions of the AIME, 146(01), 126-139. https://doi.org/10.2118/942126-G

Petalas, N., \& Aziz, K. (2000). A Mechanistic Model for Multiphase Flow in Pipes. Journal of Canadian Petroleum Technology, 39(06), 43-55. https://doi.org/10.2118/00-06-04

Poettman, F. H., \& Carpenter, P. G. (1952, January). The Multiphase Flow of Gas, Oil, and Water Through Vertical Flow Strings with Application to the Design of Gas-lift Installations. The Drilling and Production Practice.

Rawlins, E. L., \& Schellhardt, M. A. (1935). Back Pressure Data on Natural Gas Wells and Their Application to Production Practices.

Rytlewski, G. (2008). Multiple-Layer Completions for Efficient Treatment of Multilayer Reservoirs. The IADC/SPE Drilling Conference, March, 4-6.

Vogel, J. V. (1968). Inflow Performance Relationships for Solution-Gas Drive Wells. Journal of Petroleum Technology, 20(01), 83-92. https://doi.org/10.2118/1476-PA 